Trinity University

Digital Commons @ Trinity

Psychology Faculty Research

Psychology Department

1985

\title{
Cognitive Interdependence in Close Relationships
}

Daniel M. Wegner

Trinity University

T. Giuliano

Paula T. Hertel

Trinity University, phertel@trinity.edu

Follow this and additional works at: https://digitalcommons.trinity.edu/psych_faculty

Part of the Psychology Commons

Publication Details

Compatible and Incompatible Relationships

\section{Repository Citation}

Wegner, D. M., Guiliano, T., \& Hertel, P. T. (1985). Cognitive interdependence in close relationships. In W. J. Ickes (Ed.), Compatible and incompatible relationships (pp. 253-276). Springer-Verlag.

This Contribution to Book is brought to you for free and open access by the Psychology Department at Digital Commons @ Trinity. It has been accepted for inclusion in Psychology Faculty Research by an authorized administrator of Digital Commons @ Trinity. For more information, please contact jcostanz@trinity.edu. 


\title{
Chapter 11
}

\section{Cognitive Interdependence in Close Relationships}

\author{
Daniel M. Wegner, Toni Giuliano, and Paula T. Hertel
}

This chapter is concemed with the thinking processes of the intimate dyad. So, although we will focus from time to time on the thinking processes of the individual-as they influence and are influenced by the relationship with another person-our prime interest is in thinking as it occurs at the dyadic level. This may be dangerous territory for inquiry. After all, this topic resembles one that has, for many years now, represented something of a "black hole" in the social sciences - the study of the group mind. For good reasons, the early practice of drawing an analogy between the mind of the individual and the cognitive operations of the group has long been avoided, and references to the group mind in contemporary literature have dwindled to a smattering of wisecracks.

Why, then, would we want to examine cognitive interdependence in close relationships? Quite simply, we believe that much could be learned about intimacy in this enterprise, and that a treatment of this topic, enlightened by the errors of past analyses, is now possible. The debate on the group mind has receded into history sufficiently that its major points can be appreciated, and at the same time, we find new realms of theoretical sophistication in psychology regarding the operation of the individual mind. With this background, we believe it is possible to frame a notion somewhat akin to the "group mind"-and to use it to conceptualize how people in close relationships may depend on each other for acquiring, remembering, and generating knowledge.

\section{Interdependent Cognition}

Interdependence is the hallmark of intimacy. Although we are all interdependent to a certain degree, people in close relationships lead lives that are intertwined to the extreme. Certainly, the behaviors they enact, the emotions they feel, and the goals they pursue are woven in an intricate web (Davis, 1973; Kelley, Berscheid, Christensen, Harvey, Huston, Levinger, McClintock, 
Peplau, \& Peterson, 1983). But on hearing even the simplest conversation between intimates, it becomes remarkably apparent that their thoughts, too, are interconnected. Together, they think about things in ways they would not alone. The idea that is central in our analysis of such cognitive interdependence is what we term transactive memory. As will become evident, we find this concept more clearly definable and, ultimately, more useful than kindred concepts that populate the history of social psychology. As a preamble to our ideas on transactive memory, we discuss the group mind notion and its pitfalls. We then turn to a concem with the basic properties and processes of transactive memory.

\section{A Brief History of the Group Mind}

The analogy between the individual mind and the social system was extraordinarily popular among 19 th-century social theorists. Traceable in large part to the philosophies of Hegel (1807/1910) and Rousseau (1767), the tendency to draw this analogy gave rise to a variety of related ideas - the group mind, for one, but also notions of "collective consciousness," the "Volksgeist," "collective representations," the "mind of the crowd," and the "collective unconscious." Trading on the analogy was serious business at the time, and few eyebrows were raised when Herbert Spencer (1876) even went so far as to compare different brain structures to the different houses of the British Parliament.

This line of theorizing was represented in various ways in subsequent writings in sociology (e.g., Durkheim, 1915), psychology (e.g., Wundt, 1910/1916), and psychoanalysis (e.g., Jung, 1922), and formed a major theoretical rallying point for the young science of social psychology (e.g., LeBon, 1903; McDougall, 1920; Ross, 1908). In each case, some variation on the "group mind" was used as a characterization of a property of the group. Principally, this idea was used to capture within-group similarity; a group contains individuals with similar attitudes, similar understandings of the world, shared language, and otherwise seemingly unitary outlooks. Also, the group mind could represent social agency; the group seemed to behave and think as a unit, an agent that could have dealings with other agents, reflect on itself, change its mind, and in many other ways resemble an individual. Finally, the group mind provided a way of appreciating the Gestalt or configural properties of groups; the group's actions might not be reducible to those of particular individuals, and the idea of the group mind offered theorists a repository for these emergent, irreducible events.

The problem in all of this, it should come as no surprise, was that the group mind did not have a group body. Thus, there was the immediate question of where these properties of the group mind resided (see, e.g., Maclver, 1921). The more critical feature of this problem, however, was that the group mind had no voice. How would one ask the group mind a question? Would one ask the leader? In this case, the group mind is a useless concept, for its workings should 
be entirely observable in the leader's reports. Would one take a vote? In this case, the group mind concept is again valueless, for it becomes less exact than the vote itself. Would one simply observe the group? This solution was suggested by Sir Frederic Bartlett (1932), who argued that to catch the group mind at work (at least as this mind was being conceptualized by theorists at the time), one would need to observe its voiceless embodiment - the group as a whole-and find the group doing something collectively that had not been suggested or preordained by any of its individual members. Obviously, at this point the idea of the group mind loses touch with reality. For the group mind's thought to be observed in this way, a group action specifically not associated with any observable means of communication would be necessary.

Unfortunately, most of the proponents of the concept of a group mind eventually reached just this impasse. Many commentators, Bartlett included, pointed out that a group mind could be explained by the overlap of individual minds entering and leaving the group over time. The continuity and homogeneity of the group's outlook could merely be a matter of the continuous communication of group attitudes, knowledge, and customs to new members. This kind of explanation seemed entirely too common and uninteresting to group mind theorists, though, because it seemed to challenge the supposition that the group mind should be different from the minds of group members. Without this difference, of course, the group mind becomes but a superfluous addendum to the analysis of individual minds. So, in the pursuit of some unique, emergent quality of group mental life, theorists began turning to obscure avenues of explanation. Jung (1922) and Pareto (1935) sought the origins of the group mind in genetics, a topic so little understood that it could be safely adduced, along with occasional references to the supernatural, as an explanation of like-mindedness among group members. Even McDougall (1920) briefly entertained the hypothesis that telepathic communication forned the foundation of group mental life. With magic as its last recourse, the group mind concept slipped ignominiously into the history of social psychology, and by its absence ordained the study of the individual as the prime focus of the field (cf. Allport, 1968; Knowles, 1982).

Is there anything in the idea worth preserving? Along with the early theorists, we believe that an emphasis on the difference between group and individual mental processes is an indispensable part of the definition of each. At the same time, we believe that the early theorists made two critical errors in defining the group mind that must be rectified for the fiurtherance of any similar idea. First, we propose that identifying the group mind with the similar mental processes and contents of group members is an error. As will be seen, we believe that such similarity may be both a cause and a consequence of group mental operationsbut it is not the defining quality of such operations themselves. Second, we suggest that sidestepping communication processes among group members in the analysis of group mental life is an error. We hope to show that such processes are the very center of group thought, and that far fiom cheapening or demystifying the unique properties of the group mind, these communication 
processes operate to produce the distinction between the group mind and the minds of individual members. This said, it is still the case that the "group mind" terminology is steeped, perhaps forever, in error and opprobrium. Thus, we abandon such traditional language at this point, hoping to establish a more verifiable (and falsifiable) analysis by means of the idea of transactive memory.

\section{The Nature of Transactive Memory}

Ordinarily, psychologists think of memory as an individual's store of knowledge, along with the processes whereby that knowledge is constructed, organized, and accessed. So, it is fair to say that we are studying "memory" when we are concerned with how knowledge gets into the person's mind, how it is arranged in the context of other knowledge when it gets there, and how it is retrieved for later use. At this broad level of definition, our conception of transactive memory is not much different from the notion of individual memory. With transactive memory, we are concerned with how knowledge enters the dyad, is organized within it, and is made available for subsequent use by it. This analogical leap is a reasonable one as long as we restrict ourselves to considering the functional equivalence of individual and transactive memory. Both kinds of memory can be characterized as systems that, according to general system theory (von Bertalanfly, 1968), may show rough parallels in their modes of operation. Our interest is in processes that occur when the transactive memory system is called upon to perform some function for the group-a function that the individual memory system might reasonably be called upon to perform for the person.

Transactive memory can be defined in terms of two components: (1) an organized store of knowledge that is contained entirely in the individual memory systems of the group members, and (2) a set of knowledge-relevant transactive processes that occur among group members. Stated more colloquially, we envision transactive memory to be a combination of individual minds and the communication among them. This definition recognizes explicitly that transactive memory must be understood as a name for the interplay of knowledge, and that this interplay, no matter how complex, is always capable of being analyzed in terms of communicative events that have individual sources and individual recipients. By this definition, then, the thought processes of transactive memory are completely observable. The various communications that pass between intimates are, in principle, observable by outside observersjust as each intimate can observe the communications of the other. Using this line of interpretation, we recognize that the observable interaction between individuals entails not only the transfer of knowledge, but the construction of a knowledge-acquiring, knowledge-holding, and knowledge-using system that is greater than the sum of its individual member systems.

Let us consider a simple example to bring these ideas down to earth. Suppose we are spending an evening with Rudy and Lulu, a couple married for several 
years. Lulu is in another room for the moment, and we happen to ask Rudy where they got the wonderful stuffed Canadian goose on the mantle. He says, "We were in British Columbia ...," and then bellows, "Lulu! What was the name of that place where we got the goose?" Lulu returns to the room to say that it was near Kelowna or Penticton-somewhere along Lake Okanogan. Rudy says, "Yes, in that area with all the fruit stands." Lulu finally makes the identification: Peachland. In all of this, the various ideas that Rudy and Lulu exchange lead them through their individual memories. In a process of interactive cueing, they move sequentially toward the retrieval of a memory trace, the existence of which is known to both of them. And it is just possible that, without each other, neither Rudy nor Lulu could have produced the item. This is not the only process of transactive memory. Although we will speak of interactive cueing again, it is just one of a variety of communication processes that operate on knowledge in the dyad. Transactive processes can occur during the intake of information by the dyad, they can occur after information is stored and so modify the stored information, and they can occur during retrieval.

The successful operation of these processes is dependent, however, on the formation of a transactive memory structure-an organizational scheme that connects the knowledge held by each individual to the knowledge held by the other. It is common in theorizing about the thoughts and memories of individuals to posit an organizational scheme that allows the person to connect thoughts with one another-retrieving one when the other is encountered, and so forth. In a dyad, this scheme is complicated somewhat by the fact that the individual memory stores are physically separated. Yet it is perfectly reasonable to say that one partner may know, at least to a degree, what is in the other's memory. Thus, one's memory is "connected" to the other's, and it is possible to consider how information is arranged in the dyadic system as a whole. A transactive memory structure thus can be said to reside in the memories of both individuals - when they are considered as a combined system.

We should point out here that transactive processes and structures are not exclusively the province of intimate dyads. We can envision these things occurring as well in pairs of people who have just met, or even in groups of people larger than the dyad. At the extreme, one might attribute these processes and organizational capacities to whole societies, and so make transactive memory into a synonym for culture. Our conceptualization stops short of these extensions for two reasons. First, we hesitate to extend these ideas to larger groups because the analysis quickly becomes unwieldy; our framework for understanding transactive memory would need to expand geometrically as additional individuals were added to the system. Second, we refrain from applying this analysis to nonintimate relations for the simple reason that, in such dyads, there is not as much to be remembered. Close dyads share a wealth of information unique to the dyad, and use it to operate as a unit. More distant dyads, in turn, engage in transactive processes only infrequently-and in the case of a first and only encounter, do so only once. Such pairs will thus not have a very rich organizational scheme for information they hold. We find the notion 
of transactive memory most apt, in sum, for the analysis of cognitive interdependence in intimate dyads.

Our subsequent discussion of transactive memory in this chapter is fashioned to coincide with the process-structure distinction. We begin by considering the processes involved in the everyday operation of transactive memory. Here, we examine the phases of knowledge processing standardly recognized in cognitive psychology-encoding, storage, and retrieval-to determine how they occur in transactive memory. The second general section examines the nature of the organizational structure used for the storage of information in the dyad. The structure of stored information across the two individual memories will be examined, with a view toward determining how this organization impinges on the group's mental operations. The final section concentrates on the role of transactive memory, both process and structure, in the life of the dyad. We consider how such memory may contribute to compatibility or incompatibility in relationships, and how an individual's personal memory may be influenced by membership in a transactive system.

\section{Transactive Memory Processes}

Communication is the transfer of information. When communication takes place between people, we might say that information is transferred from one memory to another. However, when the dyadic group is conceptualized as having one memory system, interpersonal communication in the dyad comes to mean the transfer of information within memory. We believe that multiple transfers can occur as the dyad encodes information, as it holds information in storage, and as it retrieves information-and that such transfers can make each of these processes somewhat different from its counterpart occurring at the individual level.

\section{Transactive Encoding}

Obviously, dyads do not have their sense organs in common. The physical and social environment thus must be taken in by each person separately. Social theorists have repeatedly noted, though, that an individual's perceptions can be channeled in social ways. Many have observed, for example, that one partner might empathize with another and see the world from the other's "point of view." Alternatively, cognitive constructions of a "group perspective" may be developed by both partners that lend a certain commonality to their intake of information (see Wegner \& Giuliano, 1982). These social influences on encoding, however, are best understood as effects on the individual. How does the dyad encode information?

When partners encounter some event and encode it privately in their individual memories, they may discuss it along the way. And though we might commonly think of such a discussion as a "rehash," a mere echo of the original 
perceived event, there is reason to think that it could be much more. After all, whereas experiencing an event can be accomplished quite passively, discussing an event requires active processing of the information-and the generation of ideas relevant to the event. Several demonstrations of an individual memory phenomenon called the "generation effect" indicate that people will often remember information they have generated better than information they have simply experienced (Johnson \& Raye, 1981; Slamecka \& Graf, 1978). So, for instance, one might remember the number 37 better if one had been presented with " $14+23=$ ?" than if one had merely been presented with "37." Partners who talk over an event, generating information along the way, might thus come to an encoded verbal representation of the event that supplants their original, individual encoding.

The influence of the generation effect could, of course, take many forms. Ordinarily, it should lead partners to remember their own contributions to dyadic discussions better than the contributions of their partners. This phenomenon has been observed in several studies (e.g., Ross \& Sicoly, 1979). But the generation effect could also contribute to one's memory for group. generated information. When a couple observes some event-say, a weddingthey may develop somewhat disparate initial encodings. Each will understand that it was indeed a wedding; but only one may encode the fact that the father of the bride left the reception in a huff; the other might notice instead the odd, cardboard-like flavor of the wedding cake. Their whispered chat during all this could lead them to infer that the bride's father was upset by the strange cake. Because this interpretation was generated by the group, both partners will have thus encoded the group's understanding of the events. Their chat could thus revise history for the group, leaving both with stored memories of the father angry over a sorry cake.

Evidence from another domain of cognitive research leads to a similar point. One of the most powerful determinants of encoding in individual memory is the degree to which the incoming information is semantically elaborated (e.g., Anderson \& Reder, 1979). To elaborate incoming information is simply to draw inferences from it and consider its meaning in relation to other information. This is precisely what happens in dyadic communications about events. Partners often talk about things they have experienced as individuals or as a group. They may speak about each other's behavior, about the behavior of others they both know, about the day's events, and so on. In such discussions, it is probable that those particular events or behaviors relevant to the dyad will be discussed at length. They will be tied to other items of knowledge and, in the process, will become more elaborately encoded - and thus more likely to be available for later retrieval.

To the extent that generative or elaborative processes are effortful, or require careful thinking, their effects could be strengthened yet further. Encoding processes that are effortful for the individual typically lead to enhanced memory (Tyler, Hertel, McCallum, \& Ellis, 1979; Walker, Jones, \& Mar, 1983). When a couple engages in an argument, cognitive elfort may be required for each 
person to understand what the other is saying and for each to convey a personal point of view. Such effort on the part of both could also be necessary when one partner is merely trying to teach the other something. It is the shared experience of argument, decision-making, or careful analysis that will be remembered more readily when the communication is effortful. After all, couples more frequently remember their "talks" than their routine dinner conversations.

These transactive encoding processes could conceivably lead a dyad to understand events in highly idiosyncratic and private ways. Their discussions could go far afield, linking events to knowledge that, while strongly relevant to the dyad, is embedded primarily in the dyad's known history or anticipated future. The partners' memories of the encoded events themselves could be changed dramatically by the tenor of their discussions, sometimes to the point of losing touch with the initial realities the partners perceived. To some degree, such departures from originally encoded experience might be corrected by the partners' discussions of events with individuals outside the relationship; such outsiders would serve to introduce a perspective on events that is uninformed of the dyad's concerns, and that therefore might help to modify memory of the events. But many experiences are discussed only within the relationship, and these are thus destined to be encoded in ways that may make them more relevant to the dyad's concerns than to the realities from which they derived.

\section{Transactive Storage and Modification}

Once information gets into transactive memory, it is stored, perhaps later to be retrieved. One important concern regarding storage is the way in which the information is organized: Does one person have it, do both have it, or are there yet other possible arrangements? We take up these questions later when we explore the structure of transactive memory. At this point, we wish to dwell a bit on a different aspect of storage-its dynamic properties. One of the most intriguing lessons of cognitive research on individual information storage is that there is no guarantee that information will be retrieved from storage in the same form in which it was originally encoded. Knowledge apparently can be modified, even as it resides in memory.

Studies of individual memory by Loftus and her colleagues (e.g., Loftus, Miller, \& Burns, 1978) have shown that memory for previously perceived events can be influenced by subsequent events. Subjects who saw slides of an auto accident, for instance, and who were then asked questions containing erroneous implications about perceptual details of the accident, later falsely recognized slides depicting the implied details. Research by Hertel (1982) indicates that such modifications can also occur in an individual's memories for his or her cognitive and affective reactions to events. Information obtained well after an event can lead one to remember differently one's reaction to the event. Errors such as these may occur because information encountered subsequent to an event is integrated into one's stored representation of the event. 
A straightforward extrapolation of these phenomena would suggest that similar modifications should occur in a dyad's memory. When the couple encodes an initial event and then witnesses subsequent events relevant to it, both partners may be subject to parallel individual memory modification, and their shared memory representation might thus be modified. We believe, though, that memory modification in the dyad could be quite a bit more complicated (and interesting) because of iterative effects that occur in the course of dyadic communication. Suppose, for instance, that a female partner is surprised at a remark made by her neighbor. The neighbor called over the fence to say that "Your dog is doing a fine job of fertilizing my lawn." The male partner may have originally observed the surprise reaction, but later saw the neighbor kick the dog. Still later he might consequently misrecall that the female partner had reacted with anger to the neighbor's remark. And quite conceivably, she could come to agree with her mate's report of her anger. Through a chain of communications, both partners may modify their memory of prior events, making this memory consistent with subsequent information that the dyad has obtained.

In a broader sense, the modification of transactive memory may be an inevitable part of communication. This is because internally represented thoughts may need to be modified by the individual to make them communicable. In studies of the social transmission of information, for example, Bartlett (1932) found that sending a story through a chain of people has certain predictable effects on the nature of the story. It usually becomes a simplified, short-hand account that resolves or drops any inconsistencies that were present in the original version. A transmitted story thus resembles the protocols people give when they recall information after storing it for a long time. Communicating information between people, like storing it within one person over time, yields pared-down, "schematic" representations of the information. Of course, something like this could occur merely through sloppiness in communication. But such social degeneration of information could also be the result of modifications that one individual makes in information for the purpose of transmitting it to another. The simple fact that communicated information must be put into words, for example, requires that it be discrete as opposed to continuous (Freyd, 1983). The speaker's injunction to make things understandable to a listener, in turn, may strip away inconsistencies and irrelevancies (cf. Zajonc, 1960).

These simplification processes, in combination with the aforementioned modifiability of the individual's memory, produce a highly modifiable transactive memory. One might, for example, tell a partner about a childhood incident in which one was frightened by a duck. The experience itself could not be transmitted, of course, only the words. Even these would necessarily be brief, failing to cover the wealth of detail one originally encoded, and perhaps missing much of the context of the episode as well. Later on, one's partner might then recount this experience, probably in new words and with different emphases (e.g., "There's a duck, dear; run and hide!"). One could fail at this time to point 
out the difference between this version and one's original experience. One might even "play along," elaborating the memory by telling a story of a violent and deranged waterfowl. As a consequence of repeated interactions of this kind over time, both partners could end up sharing in memory a skeletal and decidedly incorrect version of the duck story that one had encoded quite veridically at the outset. The impact of social transmission that Bartlett observed might not need long chains of people passing rumor; it could develop through the repeated cycling of information between just two partners.

\section{Transactive Retrieval}

Retrieval is usually considered the final step of memory processing - the point at which the effectiveness of encoding and storage become known. Therefore, when a couple is called upon to retrieve information, their success will depend in large part on the nature of the transactive processes that have enabled them to encode and store the information. But even at this final step, further transactive processing may occur.

As we noted earlier, the couple might search their transactive memory in a sequential, interactive process; one partner retrieves an item of information relevant to the target item, the other uses this item as a cue for yet another item, and so on. Such interactive cueing is often observed when a couple has a shared "tip of the tongue" experience. In trying to remember the name of a film, for instance, one person might volunteer that "It begins with a $B$." The other might say, "Ooh, ooh, wait, wait," and then later mention that the film was a comedy with a Faustian theme. This image might help the first to recall that Dudley Moore's costar wore a red satin "devil" suit in part of the movie. Eventually, one or the other partner might finally hit on the name.

It is unclear whether this transactive process would usually result in more successful retrieval than would parallel individual retrieval attempts. It is fairly obvious, though, that interactive cueing of this kind could often lead to quite different retrieved information. Members of a close relationship could easily lead each other astray, along lines of inquiry that both recognize as reasonable-but which are better characterized as flights of fancy than actual recollections. At other times, however, they might have the opposite tendency, keeping each other "in line" as they pursue the target item. The predominant consequences of interactive cueing are presently unknown, for as far as we can discern, no research has been conducted to examine this process.

There is another aspect of dyadic retrieval, however, that has a somewhat more proximal empirical base. Cognitive psychologists have investigated the effects of the context of individual retrieval attempts, finding that people are better able to retrieve information in contexts that resemble the ones in which the information was encoded (Tulving \& Thomson, 1973). In our view, this finding suggests that individuals who have encoded information in the presence of an intimate will subsequently retrieve the information more effectively if the intimate is present during retrieval. The intimate partner provides an important 
context for everything one encodes for the duration of the relationship. On hearing a tune and humming it with one's partner, on gossiping about friends with the partner, and even on watching TV with the partner, there is a special context for encoded information. Later retrieval should be facilitated when the partner is present. In short, the family that encodes together should retrieve together.

This phenomenon may be responsible for the ease with which past pains in relationships are brought to mind in the presence of the other. Similarly, joys shared in the past may be retrieved primarily when the other is present. Moments shared with other people-whether old flames, parents, or even fellow workers-should be relatively more difficult to retrieve in the presence of one's current intimate partner. In a way, the co-presence of partners produces in each a special mindset, a readiness to remember the information first encountered in the same group setting.

\section{Transactive Memory Structures}

To build a transactive memory is to acquire a set of communication processes whereby two minds can work as one. To a certain degree, then, any couple that shares a common culture and language has a rudimentary transactive memory. The couple possesses a common set of background assumptions (cf. Cicourel, 1974; Clark \& Haviland, 1977; Grice, 1975; Lewis, 1969) that they share as well with everyone else in their neighborhood. Thus, they begin a relationship, even as strangers, with a certain sense that each knows something that the other knows. This basic sense, however, can grow in quite different directions as changes occur in the organization of the couple's transactive memory. For one, as intimates become acquainted, they can each come to understand that there are certain areas one knows that the other does not; this change is the differentiation of transactive structure. And also, as they become acquainted, they can develop a sharing of unique knowledge that moves beyond the basic sharing that occurs between strangers in a culture; this change is the integration of transactive structure. Both differentiation and integration are processes, of course, and so might be classed with the various transactive memory processes we have discussed thus far. Each can occur during encoding, storage, and retrieval phases of transactive knowledge processing. These processes, however, impinge most clearly on the location of information in transactive memory, and so are considered here as we address the topic of transactive structure.

\section{Differentiated Structure}

A person beginning a close relationship will enjoy a background of familiarity with certain things - family, fiiends, special interests and skills-to which the partner has never been privy. And while the partner may guess that the person 
has such realms of knowledge, and even make fairly good estimates of its nature and extensity, the partner does not really know for sure what exists in the person's individual store of knowledge. So, if the partner was having trouble, say, tying a knot, he or she would not be able to say with much confidence whether the person would be of any assistance in this enterprise. Knowing that the person had been involved in scouting as a child, however, could offer an important key. Such a fact about a person is not likely to be immediately evident, of course, and so must be acquired at some point for the partner to have any success in taking advantage of the person's expertise.

As each member of the pair becomes more cognizant of the specialties of the other, the dyad's memory as a whole grows in differentiation. To describe this feature of transactive memory more explicitly, it is useful to introduce distinctions regarding three kinds of information a person may hold in personal memory: higher-order information, lower-order information, and location information. One can think of higher-order information as the topic, theme, or gist of some set of items of lower-order information. So, for example, the term "fruit" can be considered higher-order information with respect to terms such as "apple," "orange," and "banana." By the same token, "what George said" can be regarded as higher-order information than the actual words he spoke. Distinctions like this one have been made frequently in cognitive psychology, sometimes using terms such as "schema" to refer to higher-order information. We include the distinction here to indicate simply that there are degrees of the specificity of knowledge represented in memory. Location information, in tur, is information as to where any piece of higher-order or lower-order information may be found. In a sense, it is an "address." When one knows that information on Kant's Critique of pure reason can be found in a library, in a philosopher friend's memory, or even in one's own memory, one has location information about Kant's Critique.

Communication in the dyad may lead to the transmission of any of the three types of information. Certainly, one might tell a partner of the existence of some higher-order knowledge (e.g. "Sam and Wanda were at the party") or some lower-order knowledge (e.g., "He said he was ashamed of her when she got drunk"). One would also convey location knowledge in saying these things, for one would immediately give away that these facts were available in one's own memory. It is possible, however, that one could convey location information with regard to higher-order knowledge without conveying the lower-order knowledge associated with it. Simply noting that "I heard what Sam and Wanda were talking about at the party," for example, would communicate to one's partner that one held both higher and lower orders of information in one's memory-but it would not reveal the nature of the lower-order information. In making such communications, one would contribute to the differentiation of the transactive memory structure.

A differentiated transactive structure, in this light, is one that contains mutual higher-order and location information, but reserves lower-order information for 
one or the other partner's memory alone. Knowledge of general topics is shared by both persons, and with the simultaneous sharing of location information, each person obtains a personal "directory" for knowledge held by the dyad. The individual in this system may have any amount of lower-order information. At the extreme, one person might hold all the lower-order information available to the dyad. This person could find anything that the dyad knows merely by accessing his or her own memory. The other partner, in turn, would have similar access-but would be required to access the other's memory, through communication, to obtain any item of lower-order information. More commonly, of course, couples develop differentiated structures in which each partner holds some proportion of the lower-order information accessible to the dyad.

The development of differentiated transactive memory is an important effect of the reciprocal self-disclosure that usually accompanies relationship formation. Couples typically begin a relationship by revealing information about themselves to each other; starting with fairly mundane surface information, they move on to exchange more private knowledge of themselves (cf. Altman \& Taylor, 1973: Archer, 1980). And, when they are trading knowledge of their life goals, personality traits, emotional investments, or other personal qualities, they are also building the differentiation of their transactive memory. Each fact about the self that is revealed to the other lends the other a sense of one's expertise and experience. Thus, self-disclosure regularly transmits higher-order information. Sometimes, much lower-order information is conveyed as wellsuch as when one tells the other not only that one "likes Greek food," but also details one's recipes for several Greek dishes. More commonly, though, these lower-order details will not be communicated. The other will have sufficient access to them merely by knowing the higher-order information and the location information that is communicated "piggyback" with it. In the future, when the pair wants Greek food, the expert in this domain will be expected by both parties to supply the needed lower-order information.

The differentiated organization of knowledge in the dyad makes for an efficient transactive memory. For all those domains of knowledge that the group might need to know-but that neither individual must know alone-differentiated organization eases the work of one or the other partner. Lower-order information can be communicated on a "need to know" basis, as when the Greek gourmet can direct the cooking of a mutually prepared meal, noting ingredients and steps to the other as they are necessary. And the partner who does not know the details of knowledge in a particular domain can nevertheless be confident that the dyad will be effective. To a degree, couples may even undertake to manage their affairs such that transactive memory will be differentiated. They may decide, for instance, that one should have responsibility for the group's checkbook balancing, that the other should have the responsibility for knowing about a child's progress at school, and so on. In this way, they avoid wasting transactive memory space on duplication of lower- 
order information. Indeed, such efficiency may often be produced in a relationship by virtue of partners' prior adoption of the specialized knowledge responsibilities that accompany sex roles, occupational roles, and the like.

Differentiated structure may be efficient, but it also may lead to certain problems in information management in the relationship. For instance, as higher-order information and location information are shared, and the transactive memory thus becomes differentiated and increasingly capable of accessing unshared domains of lower-order information, we would expect an increase in the pair's confidence in their knowledge in general. Organization of information regularly leads individuals toward greater confidence that they know the information (see, e.g., Pratt, Luszcz, Mackenzie-Keating, \& Manning, 1982). With differentiation, each person would become increasingly likely to believe that the group would be able to retrieve most any information-though the person might not have any access to the information in personal memory. The female who has specialized in knowlodge linked most strongly with her stereotypic sex role, for instance, may enter a relationship with a male and experience an immediate surge in confidence that her dyad will be able to fix a leaky faucet, play poker, or otherwise employ knowledge domains usually associated with the male sex role. Such presumptions may often be unfounded.

Differentiated structure could also lead on occasion to confusions regarding one's own knowledge. The "feeling of knowing" (Hart, 1967) might very well arise not only for domains that one indeed knows, but also for domains of information known only by virtue of transactive memory. If one partner keeps track of phone numbers, for example, the other may never have experienced any difficulty in retrieving a needed number. All the other must do is ask. On encountering a setting in which the partner is not present, however, the other could fail to appreciate the absence of the usual information source-and so continue to assume that the phone numbers are immediately available. Such confusions should be particularly intrusive in the very settings that usually allow for transactions between partners. At home, in familiar recreational contexts, and the like, it seldom happens that one is stranded without the other. Thus, much lower-order information may be taken for granted. Only when one must be alone will these assumptions be examined, and the extent of one's personal hold on information be discovered.

It is perhaps fortunate that transactive memory is never entirely differentiated. A conversation between partners who share little or no lower-order information, for instance, could be tiresome indeed. They would chat about generalities, but because they held no lower-order information in common, they could never get into the details of their individual domains of knowledge. They could reiterate their personal qualities and interests, delving again into the process of reciprocal self-disclosure. But eventually, they would have little new to say to each other-every higher-order item of knowledge would already be shared, and conversations would deteriorate rapidly (e.g., one says "I know every batting average in the American League"; the other says "I know you do, dear"). Given the human tendency to converse primarily about the new (Grice, 
The development of integrated transactive structures has been investigated in various guises in social psychology. Studies of group decision making (e.g., Davis, 1980; Kerr, 1981) and "social combination" processes (e.g., Laughlin, 1980) have examined the means by which groups reach integrated understandings of topics on the basis of initially disparate individual understandings. As a rule, these lines of research have indicated that groups strive toward a unity of conceptualization, a general view held by all members. This is certainly consistent with our notion of integrated transactive structure. With the present analytical framework, however, it is possible to go one step further in understanding such processes.

We believe that the press toward integrated structure in transactive memory is responsible for the unique, emergent properties of group mental life. What the group-mind theorists were searching for can be found in the seemingly "magical" transformations that occur when disparate sets of information are combined into new ideas. One partner may bring one set of knowledge, the other may bring something different, and they then may experience some conflict. But in the healthy dyadic relationship, this conflict does not necessarily lead to the dissolution of the group. Rather, it energizes the integration process, leading the couple to seek some new conceptualization that will transform their conflict into agreement. The new formulation that is reached, however, does not just promote compromise between partners. It also makes the group think about something in a way that the individuals would not; the group's viewpoint becomes unique.

This press toward unique integrations in close dyads was the topic of research by Giuliano and Wegner (1983). Their experiment was planned to induce a cohesive group state in some heterosexual pairs but not in others, and to compare the interactions of such "close" and "distant" couples during dyadic problem-solving. The problems posed to these couples were designed to resemble a typical hurdle that dyads must overcome repeatedly in daily life: The couple encounters an opportunity to retrieve a single target item from transactive memory - when each member has already retrieved a candidate item from personal memory. This could happen, say, when a couple must decide on a restaurant to visit when each partner has already thought of a possibility. The hypothesis was that "distant" couples, when faced with disagreement, would opt for the personal choice of one or the other partner; "close" couples, in contrast, were expected to use such conflict as a stimulus to invent a new, group-generated possibility. Quite simply, unique integrations would evolve in the face of conflict-but only when the couple had been induced to feel "close."

For each experimental session, two or three male/female pairs were randomly formed from a group of people who did not know one another. Pairs were taken to a room, seated at adjacent chairs facing opposite directions, and given several yards of yarn neatly wrapped around a stick. Partners were instructed to wrap the yam around the two of them, exchange places, and wrap the yarn back onto the stick-all of this in privacy, but without talking. This 
exercise was designed to induce cohesiveness between partners. Out of concern that initial negative impressions might hinder the effectiveness of the cohesiveness manipulation, the researchers had subjects anonymously rate their initial impressions of other group members immediately after everyone arrived for the session. Strong negative first impressions (prior to pairing) on the part of at least one partner led to the exclusion of three pairs from the analyses. This left a total of 16 couples to become wrapped up with each other.

The problems to be solved were patterned after TV's "Family Feud" game show. The problems consisted of 20 categories (e.g., a place to get pizza; bedtime for college students) and subjects were instructed to predict the response most commonly given by 100 undergraduates who had been polled for their opinions. In order to compare individual and group memory structures, subjects completed this questionnaire twice. They filled out the questionnaire for the first time individually, just prior to being paired for the cohesiveness manipulation. The questionnaire was filled out by pairs the second time. Half of the subjects filled out the questionnaire with their original (yarn) partners. For the other half, opposite-sex pairs were formed such that the problems were solved by partners who had not experienced the cohesiveness manipulation together. The couples were tape-recorded as they discussed the categories and tried to develop a single answer that was ostensibly to be scored for popularity against the responses of the polled undergraduates.

The typical procedure that the couples followed in selecting their final response started with each partner revealing his or her earlier response. Then, they could adopt one of several strategies for determining a dyadic response. When partners initially had a similar individual response (about $24 \%$ of the time), the dyadic response could be the same as their individual responses or it could be different. Not surprisingly, couples whose individual responses coincided chose that response for the dyad on $99 \%$ of their agreements. A much wider range of options was available when individual responses differed. In many cases, partners in this situation would simply decide on the individual response of one or the other. For questions calling for a qualitative response (e.g., naming a musical group), this of ten happened-producing a lop-sided compromise between partners. For questions of a quantitative nature (e.g., the average age that females marry for the first time), responses were often derived from the two individual responses as a true compromise between them. When the ages of 18 and 22 were given, for instance, 20 would be the dyad's response.

The final possible strategy when individual responses differed was to develop a dyadic response that resembled neither individual response. Such strategies were, of course, of special interest in this research. Rather than signifying some sort of compromise between individual responses, they represent unique integrations-choices that are unpredictable from individual responses. This happened for questions requiring either quantitative or qualitative responses. In the case of a qualitative item such as "Name a good candy bar," for instance, individual responses of Mars and Milky Way might yield a group response of 
Snickers. In the case of a quantitative item such as "Average bedtime for college students," individual responses of 12:00 AM and 1:00 AM might produce a group response of 1:30 AM.

In the parlance of transactive memory, the couples in this study were placed in the position of having a differentiated transactive structure. Each time they discussed their initial personal responses, and so communicated lower-order information, they took the chance of discovering differentiation-different items of information coming from the different personal repositories of transactive memory. Their strategies for resolving these discrepancies could then be of two types: compromise strategies, which were derived from individual structures, or integrative strategies, which were independent of them. The first type includes group responses that originated with one or the other partner, as well as responses derived as midpoints between the two individual responses. Strategies independent of individual responses are integrative in nature and uniquely represent the dyad.

The results revealed that integrative responses were the strategy of choice when "close" couples had to resolve diff" erences. The correlations between the overall number of initial differences of "close" partners and their use of integrative strategies revealed a significant relationship for both qualitative questions $[r(16)=.43, p<.05]$ and quantitative questions $[r(16)=.54$, $p<.02$ ]. For "distant" partners, the corresponding correlations revealed no significant relationships $[r(16)=.18$, qualitative; $r(16)=.00$, quantitative]. For "close" couples, therefore, initial discrepancies resulted in increased attempts to unite the pair with unique, group-generated solutions. The use of these unique integrations was not promoted by the degree of initial discrepancy for previously unpaired subjects. These results support the idea of a transactive communication process in a close dyad that prompts integrative communication whenever discrepancies in lower-order information are revealed.

The tape-recordings of the problem-solving sessions showed that couples sometimes verbally prearranged their strategy. Several couples clearly set out a "turn-taking" strategy for resolving discrepancies- "We'll do yours this time and mine next." It is interesting that commentators on group conflict resolution have of ten argued that such turn-taking is a primary cooperative response to incompatible individual preferences (e.g., Kelley \& Thibaut, 1978). The present results suggest that this is not the strategy of choice in close dyads. Close couples faced with differentiated knowledge structures of ten do not verbalize their integrative strategy, but it seems to be pursued with a certain automaticity and urgency. Asked to "Name a magazine," for example, a couple produced individual responses of People and Newsweek-and instead of discussing these at all, immediately turned to suggesting other possibilities. In some couples, the unique integration was then a good answer (e.g., Time); in others, the final choice was less appropriate (e.g., Playboy). But in all cases of integration, even though the integrative strategy was not verbally formulated by the dyad, it was rapidly adopted, cutting short the discussion of individual preferences. 
As a final note on this research, it should be pointed out that the findings signal only a first step in the investigation of transactive processes. Clearly, the results pertain primarily to ad hoc couples who have been made to feel close, not partners in ongoing close relationships. Moreover, the findings arose in a context quite unlike experiments on integrative processes in memory. Because the emphasis of this research was on transactive processes, and not on the accuracy of group retrieval of presented information, it was not necessary to develop these findings in the context of a standard memory paradigm. Until further inquiry is made into the production of unique, integrative knowledge in close relationships, the generality of the observed phenomenon-and its impact on the accuracy of transactive memory-can be anticipated only in broad outline.

\section{Transactive Memory and Intimate Life}

We have hinted at an important idea in various ways throughout the chapter, and it is time now to make the proposition explicit: A transactive memory is a fundamental component of all close relationships. We believe that the potential for transactive memory makes intimacy among humans possible, allowing them to develop a form of interdependence with each other that is both lasting and continually in flux. The immediate implications of this idea are twofold: First, a dysfunctional or incompletely operative transactive memory in a relationship should portend the breakdown of closeness; second, many of the personal difficulties that accompany the dissolution of an intimate dyad should be traceable to the absence of transactive memory. Here, we explore each of these implications in turn.

\section{Pathologies of Transactive Memory}

Perhaps the most obvious failure of transactive memory would occur if it never got started. Intimacy could not develop in a relationship if the couple never talked, if their initial personal knowledge stores were so disjunct that they had no common ground to discuss, or if they could find no way to put together their ideas into new, group-generated thoughts. In terms of our theoretical analysis, then, intimacy could fail because of a lack of transactive processes, a lack of higher-order linkages that would allow differentiation, or a lack of common lower-order knowledge stores that would allow integration.

Once a relationship has formed, the processes of communication, differentiation, and integration must continue. We suspect that communication will halt in an ongoing partnership, bringing that partnership to an end, when a gross imbalance occurs between the processes of differentiation and integration. As we have already pointed out, extreme differentiation can bring an end to a relationship because it fails to promote the sharing of lower-order information and the consequent development of unique, group-generated knowledge. But 
just as intimates with too much differentiation can be troubled by too little interdependence, intimates with too much integration can become the victims of too much interdependence.

The danger of integration in transactive memory is its capacity to produce duplication. At the outset of the integration process, partners discuss differentially known details about a common topic. In sharing these details, they develop a similar understanding based on modified details from both persons. This similar understanding will lead each partner to remember only some of the details that originated in his or her own memory, and will also convert the higher-order knowledge of the topic held by each partner into a single, shared form. A couple that only conducts integrative discussions will, over time, make many of the higher-order and lower-order integrations that are available across their fields of differentiated knowledge. Such wholesale integration could lead to the very same state of boredom with the relationship that is reached through extreme differentiation; there is nothing new to talk about. Furthermore, if each partner has the same knowledge that the other has, they each independently have access to the group memory. Neither partner requires access to the other for any information, and they thus can become functionally isolated from each other despite their apparent closeness. Contrary to its intended effect, then, integration can render transactive memory redundant and unnecessary to the individual.

Duplication can precipitate relationship problems in yet another way. Once considerable duplication has occurred-say, in a couple living together for several years-it can be assumed by parners that their own knowledge is sufficient for group-relevant judgments. In essence, each assumes that the duplication with the other is complete. A partner might know, for example, that the group typically goes out to dinner on Saturday nights, and even knows what the other will prefer to order. Thus, the partner will have no qualms about making dinner reservations for Saturday, unbeknownst to the other, and might even go on to order the entire meal for two while the other is still looking at the menu. This strategy will succeed if the duplication is indeed total-down to the partner's knowledge of which of the six available soups the other will prefer. The strategy will fail, however, whenever duplication is incomplete for any reason. The other may have been exposed to information suggesting that a new soup would be best or perhaps has just decided that the usual is becoming tiresome. The partner who assumes duplication will often fail to pick up on such subtleties, and in the end, will be rightfully accused of "taking for granted" the other.

In essence, duplication and the assumption of duplication threaten a relationship when partners believe that they know each other very well. This potential endpoint of integrative processes reminds us, then, that couples can become too familiar. It is only when couples do not share everything they know-or at least believe that not everything is shared-that their relationship will be open for further discussion and development. To a degree, this ironic twist in relationship development seems to pose quite a problem. How can 
couples who remain together for many years keep from becoming duplicates? Perhaps the only way to maintain such "freshness" in the relationship is for each partner continually to seek out domains of knowledge unknown to the other. A renewal of the diff erentiation of their transactive memory could occur every day-if the partners are willing to be apart, to experience life on their own, and to contribute to the dyad by being at least somewhat independent of it.

\section{Parting With Transactive Memory}

A couple may break up because of transactive memory, or their relationship may end in spite of it. What happens to each partner then? Amidst the emotional turmoil that can accompany partnership dissolution (Berscheid, 1983), there may also appear several cognitive effects that can throw the individual into a confused and inefficient state for some time. Certainly, the privilege of discussing events, of coming to a negotiated view of them, and of reacting to them on the basis of this group perspective will be ended. A common feeling accompanying relationship dissolution, then, will be one of indecision. A lone partner who has become used to transactive processes may almost automatically defer judgment on issues as they arise, holding off until an interpretation of events can be transacted. The person will have difficulty forming an independent and personal memory system.

With the loss of the relationship, one also loses access to the differentiated portion of transactive memory held by the other. This loss will be recognized only slowly. As one fails to find phone numbers, recipes, household objects, or the like, it begins to become evident. But more profound losses will be noted as time goes by. One's memory of favorite episodes will fade, almost inexplicably, because the other is not present to supply the differentiated details that one never stored for oneself. One will also lose the benefits of the other's special skills, never again savoring that chocolate mousse or being able to look on a flat tire as a mere inconvenience. Indeed, because transactive retrieval is no longer possible, there will be entire realms of one's experience that merely slip away, unrecognized in their departure, and never to be retri eved again.

Because the other has served of ten as a context for one's personal encoding of events, there will also be a personal deficit in retrieval. Everything one has learned in the presence of the other, even without depending on the other for transactive encoding or retrieval, will become a bit more difficult to retrieve from one's personal memory. The other has regularly served as a backdrop for one's experience, a part of the setting in which the experience was encoded. And even though the other may have played only a bystander's role in the event, one's encoding of the event is specific to the other's presence and may not allow for retrieval without the other (cf. Tulving \& Thomson, 1973). A new partner who shares some qualities with one's former intimate might serve as a substitute context, and so aid one in gaining access to one's own stored information. 
Should one become angry at the former partner, yet other changes in personal memory could result. One might renounce certain of the integrations that the group had previously achieved because they continue to be too reminiscent of the relationship. Just as the former dyad's penchant for Sunday afternoon crossword puzzles would be abandoned by the partner, their commonly held views of friends, activities, or experiences would be discarded as well. Similarly, one might attempt to stop speaking of past events in the "group" code-mentioning things that "we" did-and so disguise for oneself and others the degree of one's previous interdependence (cf. Wegner, 1981). The resentful partner could even attempt to develop new domains of expertise (e.g., "No one will ever tell me again that I can't fix a flat!") or let old ones fall into disuse. In this way, it is guaranteed that the original transactive memory developed by the group will no longer fit. Should a reconciliation be attempted, a newly negotiated transactive memory structure would be required-making for extra accommodative work on the part of the less-changed partner and perhaps a "shake-up" of the entire system.

Admittedly, some of these effects could accrue merely by losing contact with a brief acquaintance. The ending of a long-term relationship, however, will surely exact these tolls in every area of one's personal information-processing system. One will have difficulty interpreting events without discussion, and so blindly seek the advice of strangers. One will fail to encode previously differentiated information for oneself, and thus err in coping with all the nowpersonal information domains. One will abandon the dyad's integrative views of life events, perhaps to adopt less certain or satisf ying views that have only the fact that they are one's own to recommend them. And, one will simply lose contact with vast memory domains that one had hoped were personal-but that in reality were transactive, and so ended with the relationship.

Acknowledgments. We are grateful to Norbert L. Kerr, John M. Levine, Richard Machalek, David J. Schneider, William B. Swann, Jr., Robin R Vallacher, Robert A. Wicklund, and the editor of this volume for their helpful comments.

\section{References}

Allport, G. W. (1968). The historical background of modern social psychology. In G. Lindzey \& E. Aronson (Eds.), Handbook of social psychology, (2nd ed.) (Vol. I, pp. 1-80). Reading, MA: Addison-Wesley.

Altman, I., \& Taylor, D. A. (1973). Social penetration: The development of interpersonal relationships. New York: Holt, Rinehart \& Winston.

Anderson, J., \& Reder, L. (1979). Elaborative processing explanation of depth of processing. In L. S. Cermak \& F. I. M. Craik (Eds.), Levels of processing in human memory. Hillsdale, NJ: Erlbaum.

Archer, R. L. (1980). Self-disclosure. In D. M. Wegner \& R. R. Vallacher (Eds.), The self in social psychology (pp. 183-205). New York: Oxford University Press.

Bartlett, F. C. (1932). Remembering. Cambridge: Cambridge University Press. 
Berscheid, E. (1983). Emotion. In H. H. Kelley et al. (Eds.), Close relationships (pp. 110-168). New York: Freeman.

Bertalanfly, L. von (1968). General system theory. New York: Braziller.

Cicourel, A. V. (1974). Cognitive sociology. New York: Free Press.

Clark, H. H., \& Haviland, S. E. (1977). Comprehension and the given-new contract. In R. O. Freedle (Ed.), Discourse processes: Advances in research and theory (Vol. 1). Nonwood, NJ: Ablex.

Davis, J. H. (1980). Group decision and procedural justice. In M. Fishbein (Ed.), Progress in social psychology. Hillsdale, NJ: Erlbaum.

Davis, M. S. (1973). Intimate relations. New York: Free Press.

Durkheim, E. (1915). Elementary forms of the religious life. New York: Macmillan.

Freyd, J. J. (1983). Shareability: The social psychology of epistemology. Cognitive Science, 7, 191-210.

Giuliano, T., \& Wegner, D. M. (1983). Group formation and the integration of transactive memory. Unpublished manuscript, University of Texas at Austin.

Grice, H. P. (1975). Logic in conversation. In P. Cole \& J. L. Morgan (Eds.), Syntax and semantics (Vol. 3). New York: Academic Press.

Hart, J. T. (1967). Memory and the memory monitoring process. Journal of Verbal Learning and Verbal Behavior, 6, 685-691.

Hayes-Roth, B., \& Thorndyke, P. W. (1979). Integration of knowledge from text. Journal of Verbal Learning and Verbal Behavior, 18, 91-108.

Hegel, G. W. F. (1910). The phenomenology of mind (Trans.). London: Allen and Unwin. (Original work published 1807)

Hertel, P. T. (1982). Remembering reactions and facts: The influence of subsequent information. Journal of Experimental Psychology: Learning, Memory, and Cognilion, 8, 513-529.

Johnson, M. K., \& Raye, C. L. (1981). Reality monitoring. Psychological Review, 88, 67-85.

Jung, C. G. (1922). Collected papers on analytical psychology (2nd ed.). London: Bailliere, Tindall, and Cox.

Kelley, H. H., Berscheid, E., Christensen, A., Harvey, J. H., Huston, T. L., Levinger, G., McClintock, E., Peplau, L. A., \& Peterson, D. R. (1983). Close relationships. New York: Freeman.

Kelley, H. H., \& Thibaut, J. W. (1978). Interpersonal relationships: A theory of interdependence. New York: Wiley-Interscience.

Kerr, N. L. (1981). Social transition schemes: Charting the group's road to agreement. Journal of Personality and Social Psychology, 4l, 684-702.

Knowles, E. S. (1982). From individuals to group members: A dialectic for the social sciences. In W. J. Ickes \& E. S. Knowles (Eds.), Personality, roles, and social behavior (pp. 1-32). New York: Springer-Verlag.

Laughlin, P. R. (1980). Social combination processes of cooperative problem-solving groups on verbal intellective tasks. In M. Fishbein (Ed.), Progress in social psychology. Hillsdale, $\mathrm{NJ}$ : Erlbaum.

LeBon, G. (1903). The crowd. London: Allen and Unwin.

Lewis, D. K. (1969). Convention. Cambridge, MA: Harvard University Press.

Loftus, E. F., Miller, D. G., \& Burns, H. J. (1978). Semantic integration of verbal information into a visual memory. Journal of Experimental Psychology: Human Learning and Memory, 4, 19-31.

MacIver, R M. (1921). Community. New York: Macmillan.

McDougall, W. (1920). The group mind. New York: Putnam.

Pareto, V. (1935). The mind and society. New York: Harcourt-Brace.

Pratt, M. W., Luszcz, M. A., MacKenzie-Keating, S., \& Manning, A. (1982). Thinking about stories: The story schema in meta cognition. Journal of Verbal Learning and Verbal Behavior, 21, 493-505. 
Ross, E. A. (1908). Social psychology. New York: Macmillan.

Ross, M., \& Sicoly, F. (1979). Egocentric biases in availability and attribution. Journal of Personality and Social Psychology, 37, 322-336.

Rousseau, J. J. (1767). A treatise on the social contract. Iondon: Becket and DeHondt.

Slamecka, N. J., \& Graf, P. (1978). The generation effect: Delineation of a phenomenon. Journal of Experimental Psychology: Human Learning and Memory, 4, 592-604.

Spencer, H. (1876). The principles of sociology. New York: Appleton.

Tulving, E., \& Thomson, D. M. (1973). Encoding specificity and retrieval processes in episodic memory. Psychological Review, 80, 352-373.

Tyłer, S. W., Hertel, P. T., McCallum, M. C., \& Ellis, H. C. (1979). Cognitive effort and memory. Journal of Experimental Psychology: Human Learning and Memory, $5,607-617$

Walker, N., Jones, J. P., \& Mar, H. H. (1983). Encoding processes and recall of text. Memory \& Cognition, 11, 275-282.

Wegner, D. M. (1981, August). When does the intimate group come to mind? Paper presented at the meeting of the American Psychological Association, Los Angeles.

Wegner, D. M., \& Giuliano, T. (1982). The forms of social awareness. In W. J. Ickes \& E. S. Knowles (Eds.), Personality, roles, and social behavior (pp. 165-198). New York: Springer-Verlag.

Wundt, W. (1916). Elements of folk psychology (Trans.). New York: Macmillan. (Original work published 1910)

Zajonc, R. B. (1960). The process of cognitive tuning in communication. Journal of Abnormal and Social Psychology, 61, 159-167. 